\title{
REVIEW
}

\section{Aflibercept for the Treatment of Age-Related Macular Degeneration}

\author{
George Trichonas • Peter K. Kaiser
}

To view enhanced content go to www.ophthalmology-open.com

Received: May 13, 2013 / Published online: June 25, 2013

(C) The Author(s) 2013. This article is published with open access at Springerlink.com

\section{ABSTRACT}

Aflibercept is a novel, recombinant, fusion protein that consists of portions of vascular endothelial growth factor (VEGF) receptor (R) 1 and VEGFR2 extracellular domains fused to the Fc portion of human immunoglobulin G1. It exhibits higher affinity for VEGF-A/-B and binds all the VEGF isoforms (VEGF-B and -C, placental growth factor). The efficacy of aflibercept was assessed in two randomized, double-masked, multicenter, active-controlled, clinical trials in patients with choroidal neovascularization due to exudative age-related macular degeneration (AMD) and compared it's efficacy to ranibizumab, which is already Food and Drug Administration (FDA)-approved for patients with wet AMD. In the two trials known as

G. Trichonas · P. K. Kaiser $(\bowtie)$

Cole Eye Institute, Cleveland Clinic, 9500 Euclid Avenue, Desk i13, Cleveland, OH 44145, USA e-mail: pkkaiser@gmail.com

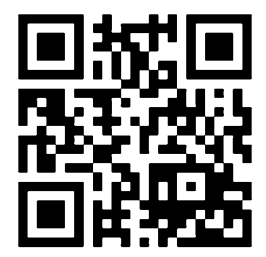

Enhanced content for this article is available on the journal web site: www.ophthalmology-open.com
VIEW 1 and VIEW 2, aflibercept was as effective when dosed as $2 \mathrm{mg}$ every 8 weeks after 3 monthly loading doses compared to monthly ranibizumab. Aflibercept was well tolerated with very rare systemic adverse events, including arterial thromboembolic events (ATEs). The incidence of ATEs was 1.8\% during the first year of the clinical trials and included non-fatal strokes, non-fatal myocardial infarction, or death from vascular events or an unknown cause. In November 2011, aflibercept received FDA approval and is currently used in clinical practice for patients with wet AMD.

Keywords: Aflibercept; Age-related macular degeneration; Angiogenesis; Choroidal neovascularization; Fusion proteins; Vascular endothelial growth factor

\section{INTRODUCTION}

Age-related macular degeneration (AMD) is the leading cause of blindness among the elderly in the developed world [1]. As the population ages, AMD has become the most common cause of vision loss [2]. In the United States (US), it 
affects more than 1.75 million people [3] and is estimated to affect approximately 14 million people worldwide. There are two forms of AMD: the non-neovascular or dry form, which is the most common, and the neovascular or wet form. The wet form of AMD is responsible for the majority of severe vision loss. Choroidal neovascularization (CNV) is the hallmark of neovascular AMD. CNV is characterized by growth of abnormal blood vessels under the macula with disruption of the blood retinal barrier, bleeding, exudation, and eventually scarring.

$\mathrm{CNV}$ has been classified into two forms: classic and occult CNV. The classification scheme was used in early AMD clinical trials. In classic CNV, the lesions show a welldemarcated appearance with early hyperfluorescence that progressively leaks dye to obscure it's boundaries in late views of the fluorescein angiogram. Occult CNV appears as either late leakage from an undetermined source at the level of the retinal pigment epithelium (RPE) or as ill-defined early leakage with less profuse leakage in late views as in classic CNV. Patients can have $100 \%$ classic or occult $\mathrm{CNV}$, but many will have mixed forms of CNV [4].

The pathogenesis of $\mathrm{CNV}$ in the setting of AMD is poorly understood. However, there are currently many reports suggesting that vascular endothelial growth factor (VEGF) plays an essential role [5-14]. Animal studies have demonstrated that VEGF over expression in the RPE leads to CNV $[15,16]$. In mouse and monkey models of laser-induced CNV, intravitreal injections of an anti-VEGF-A antibody prevented the development of CNV and reduced leakage from pre-existing $\mathrm{CNV}$ [17-20]. Since the establishment of VEGF as an important factor in the development of neovascularization, several drugs have been developed to target this molecule [21] and prevent the devastating consequences of ocular neovascularization.

Ranibizumab and bevacizumab are both VEGF inhibitors used for the treatment of AMD. Ranibizumab is a recombinant, humanized, affinity-matured, antibody fragment (Fab) that neutralizes all active isoforms of VEGF-A, and bevacizumab is a full-length, recombinant, humanized, monoclonal antibody that binds to and blocks the action of all isoforms of VEGFA [22]. Bevacizumab is used off-label for AMD as it has only received Food and Drug Administration (FDA) approval for the treatment of cancer. Two pivotal phase 3 clinical trials, MARINA [23] and ANCHOR [24], led to the FDA approval of ranibizumab. The MARINA study looked at minimally classic and occult CNV lesions comparing monthly ranibizumab to sham injections while the ANCHOR study evaluated monthly ranibizumab injections versus sham injections combined with verteporfin photodynamic therapy (PDT) in predominantly classic CNV due to AMD. The results were impressive and in both trials $94 \%$ of treated patients lost less than 15 letters of best-corrected visual acuity (BCVA) on the Early Treatment Diabetic Retinopathy Study (ETDRS) chart at 12 and 24 months. Although bevacizumab is used off-label $[25,26]$, the clinical equivalence of monthly bevacizumab and ranibizumab was recently demonstrated in the National Eye Institute's Comparison of Age-Related Macular Degeneration Treatment Trials (CATT) [27]. CATT was a 2-year, multicenter, randomized clinical trial that showed monthly dosing of both medications to be equivalent in terms of BCVA. Patients treated with ranibizumab gained +8.5 letters on the ETDRS chart whereas patients treated with bevacizumab gained +8.0 letters after 1 year of monthly injections. 


\section{METHODS}

The authors reviewed medical literature using PubMed and pertinent Internet postings combined with analysis of key studies regarding the use of aflibercept for the treatment of exudative AMD. The main keywords used were aflibercept, neovascular age-related macular degeneration, ranibizumab, vascular endothelial growth factor, wet age-related macular degeneration.

\section{FUSION PROTEINS}

Anti-VEGF monoclonal antibodies act via direct interaction with binding domains on either soluble VEGF ligands or membrane-bound receptors. In contrast, fusion proteins act as decoy receptors, binding with high affinity to the VEGF-A ligand; thus, preventing binding and subsequent activation of VEGF receptor (VEGFR) 1 and VEGFR2. The only VEGF fusion protein currently in clinical use is aflibercept [28].

\section{INTRODUCTION TO AFLIBERCEPT}

Initially, four VEGF trap molecules were constructed [29]. The parental VEGF Trap was synthesized as a fusion protein combining the constant region (Fc) of immunoglobulin G (IgG)1 with the first three domains of VEGFR1. It was found to have very strong, picomolar-binding affinity for the VEGF ligand. However, it had a significant positive charge and as a consequence bound nonspecifically to negatively charged extracellular matrix proteins, resulting in short systemic half-life $\left(t^{1} / 2\right)$. From the rest of the fusion proteins, the modification that included the $\mathrm{Fc}$ region of IgG1 fused with domain two of VEGFR1 and domain three of VEGFR2 was shown to have high affinity for the VEGF-A ligand and less positive charge. This modification increased the

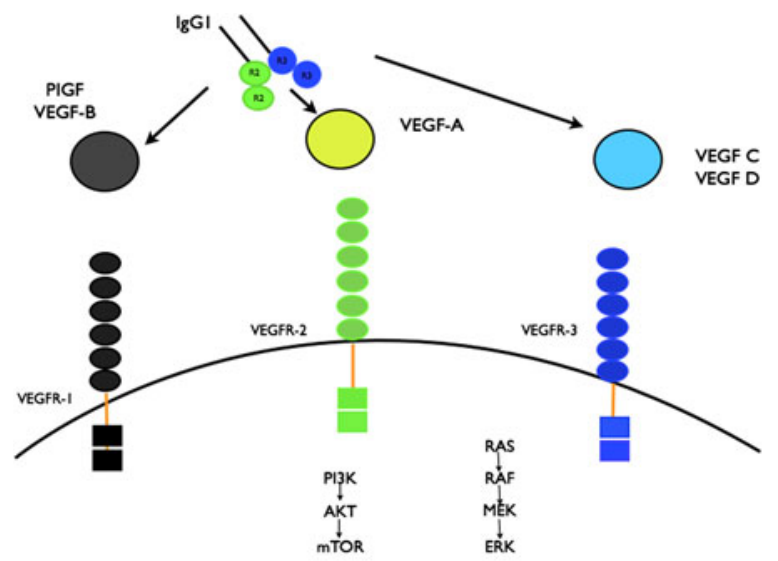

Stimulation of angiogenesis

Fig. 1 Aflibercept mechanism of action. Aflibercept binds to VEGF A-D and PIGF and prevents binding to the receptors and further activation of the angiogenesis cascade. $E R K$ extracellular signal-regulated kinase, $I g G I$ immunoglobulin G1, PI3K phosphatidylinositol 3-kinase, $P I G F$ placental growth factor, $M E K$ Mitogen-activated protein/extracellular signal-regulated kinase kinase, $m T O R$ mammalian target of rapamycin, $V E G F$ vascular endothelial growth factor, VEGFR vascular endothelial growth factor receptor

$t^{1} 12$ of the protein and its in vivo activity. This fusion protein is currently manufactured as aflibercept, which exhibits higher affinity for VEGF-A/-B and binds all the VEGF isoforms [VEGF-B and -C, placental growth factor (PlGF)] (Fig. 1).

\section{CHEMISTRY AND PHARMACOKINETICS}

Aflibercept is a soluble fusion protein. It has a molecular weight of $115 \mathrm{kDa}$ and is manufactured from Chinese hamster ovary cells that overexpress the fusion protein. Aflibercept ophthalmic molecule is identical in structure to the cancer drug, ziv-aflibercept; however, it undergoes a different purification process and the formulation contains different buffer solutions that are less irritating when injected intravitreally. 
The pharmacokinetic properties of aflibercept were initially determined by injecting VEGF TrapR1R2 (aflibercept $4 \mathrm{mg} / \mathrm{kg}$ ) subcutaneously into mice. The maximum plasma concentration $\left(C_{\max }\right)$ and area under the concentration-time curve (AUC) were $16 \mu \mathrm{g} / \mathrm{mL}$ and $36.28 \mu \mathrm{g}$ days $/ \mathrm{m}$, respectively. $\mathrm{Kd}$ for the predominant VEGF isoform in humans, VEGF165, was $0.5 \mathrm{pM}$ [30]. Bioavailability following intravenous and subcutaneous dosing was nearly identical [31]. Following intravitreal administration of aflibercept ( $2 \mathrm{mg}$ per eye), mean plasma $C_{\max }$ for free aflibercept was $0.02 \mu \mathrm{g} / \mathrm{mL}$ and was attained in $1-3$ days. The $t^{1 / 2}$ of aflibercept following intravitreal administration in humans is unknown and the predicted $t^{1 / 2}$ is based on mathematical models [32, 33]. In rabbits, the intravitreal $t^{1 / 2}$ of aflibercept is 4.6 versus 3 days for ranibizumab (Table 1) [34].

Aflibercept did not accumulate in the plasma when administered as repeated intravitreal doses every 4 weeks. Pharmacokinetic studies showed that the VEGF Trap molecule forms a 1:1 stable and inert complex with the VEGF-A ligand [35].

\section{CLINICAL EFFICACY AND SAFETY}

\section{Phase 1/2 Studies}

In a phase 1 , randomized, double-blind, placebocontrolled trial in 25 patients with subfoveal CNV from AMD, intravenous aflibercept ( 1.0 or $3.0 \mathrm{mg} /$ $\mathrm{kg}$ ) achieved a dose-dependent decrease in retinal thickness on optimal coherence tomography (OCT). However, the study was discontinued due to dose-dependent systemic toxicity, with one patient developing hypertension and another proteinuria [36]. The safety, tolerability, and biological activity of intravitreal VEGF Trap-Eye in the treatment of neovascular AMD were
Table 1 Pharmacokinetic and pharmacodynamic characteristics of aflibercept [34]

- Formulation: intravitreal injection

- Dose: $2 \mathrm{mg}$ in $0.05 \mathrm{~mL}$

- Dosing: every month for 3 months and then every 2 months

Pharmacokinetics

- Time to peak intraocular concentration: immediately following dose

- Volume of distribution: $4 \mathrm{~mL}$

- Half-life: 4.6 days

Pharmacodynamics

- Targets: VEGFA-D, PIGF

- Effect: prevents VEGF receptor activation and stimulation of the angiogenesis cascade

PIGF placental growth factor, VEGF vascular endothelial growth factor

evaluated in the Clinical Evaluation of Antiangiogenesis in the Retina-1 (CLEAR-IT-1) study [37]. During this phase 1 study, 21 patients were monitored for safety, changes in foveal thickness on OCT, BCVA, and lesion size on fluorescein angiography (FA) for 6 weeks. No adverse systemic or ocular events were noted and visual acuity remained stable or improved $\geq 3$ lines in $95 \%$ of patients with a mean increase in BCVA of 4.6 letters at 6 weeks [36]. Patients had a substantial decrease in foveal thickness on OCT.

This was followed by the phase 2 CLEAR-IT 2 trial, a prospective, randomized, multicenter, trial evaluating VEGF Trap-Eye at different doses and dosing intervals. Patients $(n=157)$ were randomized to five dose groups and treated with VEGF Trap-Eye in one eye. Two groups received monthly doses of either 0.5 or $2.0 \mathrm{mg}$ for 12 weeks (at weeks 0, 4, 8, and 12) and three groups received 3-monthly doses of $0.5,2.0$, or $4.0 \mathrm{mg}$ for 12 weeks (at weeks 0 and 12). Following this initial dosing period, patients 
Table 2 Phase 3 clinical trials of aflibercept in AMD [40]

\begin{tabular}{|c|c|c|c|c|c|c|}
\hline & \multicolumn{3}{|l|}{ VIEW 1} & \multicolumn{3}{|l|}{ VIEW 2} \\
\hline & $\begin{array}{l}\text { Aflibercept } \\
2 \text { mg } \\
\text { q8 weeks }\end{array}$ & $\begin{array}{l}\text { Aflibercept } \\
2 \text { mg } \\
\text { q4 weeks }\end{array}$ & $\begin{array}{l}\text { Ranibizumab } \\
0.5 \text { mg } \\
\text { q4 weeks }\end{array}$ & $\begin{array}{l}\text { Aflibercept } \\
2 \text { mg } \\
\text { q8 weeks }\end{array}$ & $\begin{array}{l}\text { Aflibercept } \\
2 \text { mg } \\
\text { q4 weeks }\end{array}$ & $\begin{array}{l}\text { Ranibizumab } \\
0.5 \text { mg } \\
\text { q4 weeks }\end{array}$ \\
\hline Number of patients & $n=301$ & $n=304$ & $n=304$ & $n=306$ & $n=309$ & $n=291$ \\
\hline Maintenance of VA \% & $94 \%$ & $95 \%$ & $94 \%$ & $95 \%$ & $95 \%$ & $95 \%$ \\
\hline $\begin{array}{l}\text { Mean VA improvement } \\
\text { in letters by ETDRS }\end{array}$ & 7.9 & 10.9 & 8.1 & 8.9 & 7.6 & 9.4 \\
\hline $\begin{array}{l}\text { 3-line improvement on } \\
\text { the ETDRS chart \% }\end{array}$ & $31 \%$ & $38 \%$ & $31 \%$ & $31 \%$ & $29 \%$ & $34 \%$ \\
\hline
\end{tabular}

$A M D$ age-related macular degeneration, ETDRS Early Treatment Diabetic Retinopathy Study, VA visual acuity, VIEW Vascular endothelial Growth Factor (VEGF) Trap-Eye: Investigation of efficacy and safety in wet age-related macular degeneration

were treated with the same dose of VEGF TrapEye on an as-required basis until week 52. After 12 weeks of treatment, there was a mean decrease in central retinal thickness of $119 \mu \mathrm{m}$ from baseline in all groups. Improvements in visual acuity and retinal thickness were greater in the monthly dosing groups compared with the 3-monthly dosing groups, showing a clear benefit from initial monthly injections. Patients initially dosed on a $2.0 \mathrm{mg}$ monthly schedule received an average of 1.6 more injections and those initially dosed on a $0.5 \mathrm{mg}$ monthly schedule received an average of 2.5 injections. The median time to first reinjection in all groups was 129 days and $19 \%$ of patients required no more injections at week 52 . Patients in the 2 monthly dosing groups also exhibited mean decreases in retinal thickness of $143 \mu \mathrm{m}$ in the $2.0 \mathrm{mg}$ group $(P<0.0001)$ and $125 \mu \mathrm{m}$ in the $0.5 \mathrm{mg}$ group $(P<0.0001)$ at 52 weeks as measured by OCT $[38,39]$.

\section{Phase 3}

VIEW 1 and VIEW 2 (VEGF Trap-Eye: Investigation of efficacy and safety in wet AMD) were pivotal phase 3, double-masked, randomized, multicenter studies comparing aflibercept and ranibizumab in patients with wet AMD. VIEW 1 enrolled 1,217 patients in the US and Canada and VIEW 2 enrolled 1,240 patients in the European Union, Asia Pacific, Japan, and Latin America. Both studies evaluated the percentage of patients who maintained visual acuity, defined as loss of fewer than 15 letters of BCVA on the ETDRS chart (3 lines) at 52 weeks. Patients were treated with three different aflibercept dosing regimens, $0.5 \mathrm{mg}$ every 4 weeks, $2 \mathrm{mg}$ every 4 weeks, and $2 \mathrm{mg}$ every 8 weeks (following 3 initial monthly injections), compared to ranibizumab $0.5 \mathrm{mg}$ every 4 weeks. At 52 weeks, the VIEW 1 study showed that in the aflibercept groups, vision was maintained in $96 \%$ of patients receiving $0.5 \mathrm{mg}$ monthly, $95 \%$ of patients receiving $2 \mathrm{mg}$ monthly, and $95 \%$ of patients receiving $2 \mathrm{mg}$ every 2 months, which was non-inferior and clinically equivalent to the group receiving ranibizumab $0.5 \mathrm{mg}$ monthly, where $94 \%$ of patients maintained vision [40]. VIEW 2 results were almost identical. In the aflibercept groups, vision was maintained in $96 \%$ of patients receiving aflibercept $0.5 \mathrm{mg}$ monthly, $96 \%$ of patients receiving $2 \mathrm{mg}$ monthly, and $96 \%$ of 
patients receiving $2 \mathrm{mg}$ every 2 months. In the group receiving ranibizumab $0.5 \mathrm{mg}$ monthly, $94 \%$ of patients maintained vision (Table 2) [40]. Based on these phase 3 results, aflibercept received FDA approval for the treatment of wet AMD in November 2011. The approved dose was $2 \mathrm{mg}$ and the approved treatment regimen was a loading dose of 3 monthly injections followed by dosing every 8 weeks thereafter. The 2-year results were recently announced by Regeneron Pharmaceuticals, Inc. and showed sustained improvement in visual acuity. During the second year, patients received treatment on an as-required basis, when met specific treatment criteria, but at least one injection every 12 weeks [40]. In an integrated analysis of the VIEW 1 and VIEW 2 studies, the visual acuity gain from baseline in the aflibercept $2 \mathrm{mg}$ every 8 weeks group at week 96 was +7.6 letters (versus +8.4 letters at week 52 ), with an average of 11.2 injections over 2 years and 4.2 injections during the second year. The visual acuity gain from baseline in the monthly ranibizumab group at week 96 was +7.9 letters (versus +8.7 letters at week 52, with an average of 16.5 injections over 2 years and 4.7 injections during the second year) [40]. Regarding the anatomical results, all aflibercept groups achieved reductions in central retinal thickness similar to those for monthly ranibizumab as assessed by OCT. Initially, there was a large and rapid reduction in retinal thickness evident by week 4 that was maintained to week 52. Minor fluctuations in central retinal thickness were seen in the $2 \mathrm{mg}$ every 2 months group after sham injections in the VIEW 2 study. However, these fluctuations attenuated over time [40]. Aflibercept was well tolerated with very rare systemic adverse events, including arterial thromboembolic events (ATEs). The incidence of ATEs was $1.8 \%$ during the first year of the clinical trials and included non-fatal strokes, non-fatal myocardial infarction, or death from vascular events or an unknown cause. When compared to ranibizumab, differences were noted in the pre-specified analyses of intraocular pressure, with fewer aflibercepttreated patients experiencing an increase in intraocular pressure over the 52 weeks in the VIEW 1 and VIEW 2 studies.

\section{DISCUSSION}

Anti-VEGF therapy has improved the quality of life of patients with neovascular AMD. Ranibizumab was the first medication to not only preserve but also improve vision in patients with wet AMD. The MARINA [23] and ANCHOR [24, 41] trials established ranibizumab as an effective therapy when dosed monthly. It has been shown to stabilize vision in $94 \%$ of patients and to actually improve vision by 3 or more lines in almost $40 \%$ of patients. The PIER [42] trials showed that ranibizumab is less effective when dosed quarterly or as needed. The PRONTO study, a single investigatorsponsored trial, showed that it is possible to extend the time between as-needed injections when patients are followed closely with frequent examinations and OCT testing [43, 44]. On the other hand, there is a subcategory of patients who show little if any response to therapy with persistent or rebound increase in macular fluid. Usually patients who receive three consecutive injections of ranibizumab without anatomical resolution of intraretinal or subretinal fluid are defined as nonresponders. For these patients, biweekly dosing of the medication is recommended [45].

VEGF Trap-Eye differs from established antiVEGF therapies, having a higher binding affinity for VEGF-A and VEGF-B as well as 
PIGF. Phase 1 data demonstrated acceptable safety and tolerability of VEGF Trap-Eye in the treatment of neovascular AMD. In phase 2 studies, patients dosed in a similar fashion to ranibizumab demonstrated stabilization of their vision at 1 year. Two phase 3 studies showed at year 1 that aflibercept can be dosed every 2 months after three initial monthly injections with equivalent results to monthly ranibizumab. During the second year, the number of as-required injections is less compared to ranibizumab. Furthermore, a recent retrospective study showed that patients who do not respond to ranibizumab have better visual and anatomical outcomes when switched to aflibercept [46].

Currently, the main issue with anti-VEGF therapy is the cost and the number of office visits per patient [47]. At a cost of approximately $\$ 2,000$ per injection, the cost to treat wet AMD patients in the US exceeds $\$ 10$ billion per year. The CATT study showed that bevacizumab, which costs $\$ 15-50$ per injection, has similar efficacy to ranibizumab when dosed monthly. Due to the high cost, many ophthalmologists have turned to bevacizumab as the alternative intravitreal agent in the treatment of wet AMD. On the other hand, aflibercept is more expensive than bevacizumab, but as effective as ranibizumab when dosed bimonthly and offers the advantage of less frequent injections. Every intraocular injection poses a risk of infection ( 1 in 4,000 to 1 in 8,000) and is uncomfortable for the patient. The decision of which medication to choose should be based on the clinician's judgment and the patient's response to treatment. Conducting another clinical trial comparing all three medications would be an option, but we would most likely fail to show a clear difference since all medications appear effective using their labeled dosing regimen.
Therefore, the clinician needs to decide which medication to use based on each individual circumstance. However, the cost of treatment, insurance coverage, and frequency of injections seem to alter therapy on an individual basis.

\section{FUTURE PERSPECTIVE}

Aflibercept is one of three effective medications for the treatment of neovascular AMD. The true impact of this drug is that it has a longer $t^{1 / 2}$ and higher binding affinity for VEGF-A; therefore, it can reduce the number of intraocular injections and office visits. This was the rational and the benefit behind the development of this new medication. However, neither of the available medications causes complete regression of the choroidal neovascular membrane, which is the hallmark of the disease. Based on the natural history of the disease, the abnormal capillaries that constitute the membrane continue leaking fluid until a scar is formed in the macula and the patient becomes legally blind. The focus over the next decade will be to identify new targets that can prevent or reverse choroidal revascularization. Also, it is of utmost importance to develop even longer-acting therapies. Slow-release implant formulations of current medications (e.g., ranibizumab reservoirs) are under investigation, but hold many technical difficulties given the nature and the molecular weight of the medications. Different drug formulations that could be used and eye drops are another solution to the problem of monthly injections, but so far all the drugs that have been tested have failed. Currently, there are many drugs under investigation (e.g., platelet-derived growth factor inhibitors) and the primary effect is inhibition of angiogenesis. With so many new effective agents against angiogenesis, we have an obligation to continue translational and clinical research to identify new treatments for AMD. 


\section{ACKNOWLEDGMENTS}

No funding or sponsorship was received for the publication of this article. Dr Kaiser is the guarantor for this article, and takes responsibility for the integrity of the work as a whole.

Conflict of interest. George Trichonas has no conflict of interest to declare. Peter Kaiser: is a consultant for Regeneron, Genentech, Novartis, Alcon, and Bayer. The Cole Eye Institute has received research grant support from Regeneron, Novartis, Genentech, and Alcon.

Open Access. This article is distributed under the terms of the Creative Commons Attribution Noncommercial License which permits any noncommercial use, distribution, and reproduction in any medium, provided the original author(s) and the source are credited.

\section{REFERENCES}

1. Van Newkirk MR, Nanjan MB, Wang JJ, et al. The prevalence of age-related maculopathy: the visual impairment project. Ophthalmology. 2000;107: 1593-600.

2. Weih LM, VanNewkirk MR, McCarty CA, Taylor HR. Age-specific causes of bilateral visual impairment. Arch Ophthalmol. 2000;118:264-9.

3. Friedman DS, O'Colmain BJ, Muñoz B, et al. Prevalence of age-related macular degeneration in the United States. Arch Ophthalmol. 2004;122: 564-72.

4. Guyer DR, Yannuzzi LA, Slakter JS, et al. Classification of choroidal neovascularization by digital indocyanine green videoangiography. Ophthalmology. 1996;103:2054-60.

5. Aiello LP, Pierce EA, Foley ED, et al. Suppression of retinal neovascularization in vivo by inhibition of vascular endothelial growth factor (VEGF) using soluble VEGF-receptor chimeric proteins. Proc Natl Acad Sci USA. 1995;92:10457-61.
6. Kvanta A, Algvere PV, Berglin L, Seregard S. Subfoveal fibrovascular membranes in age-related macular degeneration express vascular endothelial growth factor. Invest Ophthalmol Vis Sci. 1996;37: 1929-34.

7. Frank RN, Amin RH, Eliott D, Puklin JE, Abrams GW. Basic fibroblast growth factor and vascular endothelial growth factor are present in epiretinal and choroidal neovascular membranes. Am J Ophthalmol. 1996;122:393-403.

8. Kliffen M, Sharma HS, Mooy CM, et al. Increased expression of angiogenic growth factors in agerelated maculopathy. Br J Ophthalmol. 1997;81: 154-62.

9. Matsuoka M, Ogata N, Otsuji T, Nishimura T, Takahashi K, Matsumura M. Expression of pigment epithelium derived factor and vascular endothelial growth factor in choroidal neovascular membranes and polypoidal choroidal vasculopathy. Br J Ophthalmol. 2004;88:809-15.

10. Bhutto IA, McLeod DS, Hasegawa T, Kim SY, Merges C, Tong P, Lutty GA. Pigment epithelium-derived factor (PEDF) and vascular endothelial growth factor (VEGF) in aged human choroid and eyes with age-related macular degeneration. Exp Eye Res. 2006;82:99-110.

11. Geisen P, McColm JR, Hartnett ME. Choroidal endothelial cells transmigrate across the retinal pigment epithelium but do not proliferate in response to soluble vascular endothelial growth factor. Exp Eye Res. 2006;82:608-19.

12. Ishibashi $\mathrm{T}$, Hata $\mathrm{Y}$, Yoshikawa H, et al. Expression of vascular endothelial growth factor in experimental choroidal neovascularization. Graefes Arch Clin Exp Ophthalmol. 1997;235: 159-67.

13. Ikeda $\mathrm{Y}$, Yonemitsu $\mathrm{Y}$, Onimaru $\mathrm{M}$, et al. The regulation of vascular endothelial growth factors (VEGF-A, -C, and -D) expression in the retinal pigment epithelium. Exp Eye Res. 2006;83:1031-40.

14. Miller JW, Adamis AP, Shima DT, et al. Vascular endothelial growth factor/vascular permeability factor is temporally and spatially correlated with ocular angiogenesis in a primate model. Am J Pathol. 1994;145:574-84.

15. Cui JZ, Kimura H, Spee C, Thumann G, Hinton DR, Ryan SJ. Natural history of choroidal neovascularization induced by vascular endothelial growth factor in the primate. Graefes Arch Clin Exp Ophthalmol. 2000;238:326-33.

16. Vinores SA, Xiao WH, Aslam S, et al. Implication of the hypoxia response element of the VEGF promoter 
in mouse models of retinal and choroidal neovascularization, but not retinal vascular development. J Cell Physiol. 2006;206:749-58.

17. Krzystolik MG, Afshari MA, Adamis AP, et al. Prevention of experimental choroidal neovascularization with intravitreal anti-vascular endothelial growth factor antibody fragment. Arch Ophthalmol. 2002;120:338-46.

18. Tolentino MJ, Brucker AJ, Fosnot J, et al. Intravitreal injection of vascular endothelial growth factor small interfering RNA inhibits growth and leakage in a nonhuman primate, laser-induced model of choroidal neovascularization. Retina. 2004;24: 132-8.

19. Reich SJ, Fosnot J, Kuroki A, et al. Small interfering RNA (siRNA) targeting VEGF effectively inhibits ocular neovascularization in a mouse model. Mol Vis. 2003;9:210-26.

20. Cashman SM, Bowman L, Christofferson J, KumarSingh R. Inhibition of choroidal neovascularization by adenovirus-mediated delivery of short hairpin RNAs targeting VEGF as a potential therapy for AMD. Invest Ophthalmol Vis Sci. 2006;47: 3496-504.

21. Yu L, Liang $\mathrm{XH}$, Ferrara N. Comparing protein VEGF inhibitors: in vitro biological studies. Biochem Biophys Res Commun. 2011;408:276-81.

22. Ferrara N, Damico L, Shams N, et al. Development of ranibizumab, an anti-vascular endothelial growth factor antigen binding fragment, as therapy for neovascular age related macular degeneration. Retina. 2006;26:859-70.

23. Rosenfeld PJ, Brown DM, Heier JS, et al. Ranibizumab for neovascular age-related macular degeneration. N Engl J Med. 2006;355:1419-31.

24. Brown DM, Kaiser PK, Michels $M$, et al. Ranibizumab versus verteporfin for neovascular age-related macular degeneration. N Engl J Med. 2006;355:1432-44.

25. Moreno SF, Paloma JB. Therapeutic anti-VEGF in age-related macular degeneration: ranibizumab and bevacizumab controversy. $\mathrm{Br} \mathrm{J}$ Ophthalmol. 2008;92:866-7.

26. Ladas ID, Karagiannis DA, Rouvas AA, et al. Safety of repeat intravitreal injections of bevacizumab versus ranibizumab: our experience after 2,000 injections. Retina. 2009;29:313-8.

27. Martin DF, Maguire MG, Ying GS, CATT Research Group, et al. Ranibizumab and bevacizumab for neovascular age-related macular degeneration. N Engl J Med. 2011;364:1897-908.
28. Aflibercept: AVE 0005, AVE 005, AVE0005, VEGF Trap-Regeneron, VEGF Trap (R1R2), VEGF Trap-Eye. Drugs RD. 2008;9:261-9.

29. Holash J, Davis S, Papadopoulos N, et al. VEGF-trap: a VEGF blocker with potent antitumor effects. Proc Natl Acad Sci USA. 2002;99:11393-8.

30. Papadopoulos N, Martin J, Ruan Q, et al. Binding and neutralization of vascular endothelial growth factor (VEGF) and related ligands by VEGF Trap, ranibizumab and bevacizumab. Angiogenesis. 2012;15:171-85.

31. Rudge JS, Holash J, Hylton D, et al. VEGF Trap complex formation measures production rates of VEGF, providing a biomarker for predicting efficacious angiogenic blockade. Proc Natl Acad Sci USA. 2007;104:18363-70.

32. Stewart MW, Rosenfeld PJ. Predicted biological activity of intravitreal VEGF trap. $\mathrm{Br} \mathrm{J}$ Ophthalmol. 2008;92:667-8.

33. Stewart MW. What are the half-lives of ranibizumab and aflibercept (VEGF Trap-eye) in human eyes? Calculations with a mathematical model. Eye Rep. 2011;1:e5. http://www.pagepressjournals.org/index. php/eye/article/view/eye.2011.e5. Accessed May 30, 2013

34. Gaudreault J, Fei D, Rusit J, et al. Preclinical pharmacokinetics of ranibizumab (rhuFabV2) after a single intravitreal administration. Invest Ophthalmol Vis Sci. 2005;46:726-33.

35. Furfine E, Coppi A, Koehler-Stec E, Zimmer E, Tu W, Struble C. Pharmacokinetics and ocular tissue penetration of VEGF Trap after intravitreal injections in rabbits. Invest Ophthalmol Vis Sci. 2006;47:E-abstract 1430 .

36. Nguyen QD, Shah SM, Hafiz G, et al. A phase I trial of an IV-administered vascular endothelial growth factor trap for treatment in patients with choroidal neovascularization due to age-related macular degeneration. Ophthalmology. 2006;113:1522.

37. Nguyen QD, Shah SM, Browning DJ. al. A phase I study of intravitreal vascular endothelial growth factor trap-eye in patients with neovascular agerelated macular degeneration. Ophthalmology. 2009;116:2141-8.

38. Heier JS, Boyer D, Nguyen QD, et al. The 1-year results of CLEAR-IT 2, a phase 2 study of vascular endothelial growth factor trap-eye dosed as-needed after 12-week fixed dosing. Ophthalmology. 2011;118:1098-106.

39. Brown DM, Heier JS, Ciulla T, et al. Primary endpoint results of a phase II study of vascular 
endothelial growth factor trap-eye in wet agerelated macular degeneration. Ophthalmology. 2011;118:1089-97.

40. Heier JS, Brown DM, Chong V, VIEW 1 and VIEW 2 Study Groups, et al. Intravitreal aflibercept (VEGF trap-eye) in wet age-related macular degeneration. Ophthalmology. 2012;119:2537-48.

41. Brown DM, Michels M, Kaiser PK, et al. Ranibizumab versus verteporfin photodynamic therapy for neovascular age-related macular degeneration: two-year results of the ANCHOR study. Ophthalmology. 2009;116:57-65.

42. Regillo CD, Brown DM, Abraham P, et al. Randomized, double-masked, sham-controlled trial of ranibizumab for neovascular age-related macular degeneration: PIER Study year 1. Am J Ophthalmol. 2008;145:239-48.

43. Lalwani GA, Rosenfeld PJ, Fung AE, et al. A variabledosing regimen with intravitreal ranibizumab for neovascular age-related macular degeneration: year 2 of the PrONTO Study. Am J Ophthalmol. 2009;148:43-58.
44. Fung AE, Lalwani GA, Rosenfeld PJ, et al. An optical coherence tomography-guided, variable dosing regimen with intravitreal ranibizumab (Lucentis) for neovascular age-related macular degeneration. Am J Ophthalmol. 2007;143:566-83.

45. Steward MW, Rosenfeld PJ, Penha FM, et al. Pharmacokinetic rationale for dosing every 2 weeks versus 4 weeks with intravitreal ranibizumab, bevacizumab, and aflibercept (vascular endothelial growth factor Trap-eye). Retina. 2012;32:434-57.

46. Kumar N, Marsiglia M, Mrejen S, et al. Visual and anatomical outcomes of intravitreal aflibercept in eyes with persistent subfoveal fluid despite previous treatments with ranibizumab in patients with neovascular age-related macular degeneration. Retina. 2013 Mar 30 [Epub ahead of print].

47. Rosenfeld PJ. United States Special Committee on Aging. A prescription for savings: reducing drug costs to Medicare. Testimony before the Senate Special Committee on Aging. 21 July, 2011. http://aging.senate.gov/events/hr236pr.pdf. Accessed April 13, 2011. 